\title{
Tangential beam IMRT versus tangential beam 3D-CRT of the chest wall in postmastectomy breast cancer patients: A dosimetric comparison
}

\author{
Volker Rudat ${ }^{1 *}$, Abdul Aziz Alaradi', Adel Mohamed', Khaled Al-Yahya', Saleh Altuwaijiri
}

\begin{abstract}
Background: This study evaluates the dose distribution of reversed planned tangential beam intensity modulated radiotherapy (IMRT) compared to standard wedged tangential beam three-dimensionally planned conformal radiotherapy (3D-CRT) of the chest wall in unselected postmastectomy breast cancer patients

Methods: For 20 unselected subsequent postmastectomy breast cancer patients tangential beam IMRT and tangential beam 3D-CRT plans were generated for the radiotherapy of the chest wall. The prescribed dose was 50 Gy in 25 fractions. Dose-volume histograms were evaluated for the PTV and organs at risk. Parameters of the dose distribution were compared using the Wilcoxon matched pairs test.

Results: Tangential beam IMRT statistically significantly reduced the ipsilateral mean lung dose by an average of $21 \%$ (1129 cGy versus 1437 cGy). In all patients treated on the left side, the heart volume encompassed by the $70 \%$ isodose line (V70\%; 35 Gy) was reduced by an average of $43 \%$ (5.7\% versus 10.6\%), and the mean heart dose by an average of 20\% (704 cGy versus 877 cGy). The PTV showed a significantly better conformity index with IMRT; the homogeneity index was not significantly different.
\end{abstract}

Conclusions: Tangential beam IMRT significantly reduced the dose-volume of the ipsilateral lung and heart in unselected postmastectomy breast cancer patients.

\section{Background}

Breast cancer is the most common cancer in females worldwide. In the United States and Europe, the most common treatment is breast conserving surgery followed by adjuvant radiotherapy [1]. In other parts of the world including the Middle East, the majority of the patients present in a more advanced stage of disease at diagnosis, and mastectomy is the most common treatment followed by adjuvant radiotherapy of the chest wall [2].

Large prospective trials [3] and a meta-analysis [4] have shown that adjuvant radiotherapy of the chest wall improves local control and survival in node positive breast cancer patients after mastectomy. The adjuvant radiotherapy of the chest wall is commonly achieved with tangential beams, similar to the treatment technique used for the adjuvant whole breast radiation in

\footnotetext{
* Correspondence: vrudat@saad.com.sa

'Department of Radiation Oncology, Saad Specialist Hospital, P.O. Box 30353,

Al Khobar 31952, Saudi Arabia

Full list of author information is available at the end of the article
}

early breast cancer. The tangential beams include part of the anterior thoracic cavity, thereby potentially affecting the organs at risk, in particular the lung and heart.

Randomized, retrospective and population based studies have shown that the radiotherapy of the chest wall is associated with a significantly increased risk of developing ipsilateral second lung cancer [5-12], and in patients treated on the left side with a significantly increased risk of cardiac morbidity and mortality [4,13-24].

There is a good body of literature showing that inversed planned intensity modulated radiotherapy (IMRT) potentially leads to a more favourite dose distribution compared to three-dimensional planned conformal radiotherapy (3D-CRT) for the radiotherapy of the whole breast after breast conserving surgery [25-48]. Data on the effect of IMRT of the chest wall in postmastectomy breast cancer patients are scarce in the literature [49-51]. There are distinct differences between the target volume of the chest wall and the whole

\section{() Biomed Central}


breast. The shape of the target volume of the chest wall is usually shallower compared to the whole breast. In addition, in stage I-IIa patients the pectoralis muscle, chest wall muscles, and ribs may be excluded in the target volume of the whole breast, whereas these structures are included in the target volume of the chest wall. Due to these differences in the target volume, results of a dosimetric study of the radiotherapy of the whole breast may not be completely applicable to the radiotherapy of the chest wall.

This study specifically evaluates the dose distribution of tangential beam IMRT of the chest wall in postmastectomy breast cancer patients compared to tangential beam 3D-CRT.

\section{Methods}

\section{Patient data}

For 20 unselected consecutive postmastectomy breast cancer patients an opposed tangential beam IMRT plan and a standard opposed tangential beam 3D-CRT plan was generated for the radiotherapy of the chest wall. Thirteen patients had right-sided breast cancer and seven left-sided. The target volumes were defined and the dose prescribed according to the International Commission on Radiation Units and Measurement (ICRU) Reports 50 and 62 recommendations. Accordingly, the target volume should be surrounded by the $95 \%$ isodose line. The planning target volume (PTV) definition for the chest wall was done according to the breast cancer atlas for radiation therapy planning consensus definitions of the Radiation Therapy Oncology Group (RTOG) http://www.rtog.org/CoreLab/ContouringAtlases/BreastCancerAtlas.aspx. The PTV included the chest wall with the pectoralis muscle, chest wall muscles, and ribs, and excluded the outermost $3 \mathrm{~mm}$ from the superficial skin surface. The heart was defined as all visible myocardium, from the apex to the right auricle, atrium, and infundibulum of the ventricle. The pulmonary trunk, root of the ascending aorta, and superior vena cava were excluded.

This retrospective planning study was approved by the Institutional Review Board and Ethics committee. For the statistical analysis, the patient data were anonymized to guarantee privacy.

\section{Treatment techniques}

A non-contrast CT-simulation was performed in the supine position on a carbon breast board with the ipsilateral arm up and head turned to the contralateral side. Radio-opaque wires were used to mark the mastectomy scar and the clinical boundaries. A CT scan was performed using $5 \mathrm{~mm}$ slice thickness. The CT scanning reference point was defined using the $\mathrm{CT}$ simulation software Coherence Dosimetrist (Siemens Medical), and target volumes (PTV and organs at risk) using the software Coherence Oncologist (Siemens Medical). The 3DCRT and IMRT plans were generated using the treatment planning system XIO 4.4 (CMS, Inc. of St. Louis, Mo, USA). A Siemens Oncor Anvantgarde linear accelerator with dual photon energy of $6 \mathrm{MV}$ and $15 \mathrm{MV}$ and multileaf collimator was used for the treatment. The leaf width was $1 \mathrm{~cm}$ at the isocenter. The dose calculation was determined using the "Superposition" algorithm. The prescribed total dose was 50 Gy in 25 fractions. The beam energy of $6 \mathrm{MV}$ was used for all 3D-CRT and IMRT plans because of the better dose coverage of the chest wall due the lower penetration power compared to $15 \mathrm{MV}$.

\section{Tangential beam 3D-CRT}

The dose was prescribed to the ICRU reference point which was usually the isocenter located in the PTV volume centroid. Two tangential semi-opposed beams (to avoid divergence), physical wedges (usually $15^{\circ}$ or $30^{\circ}$ ), and a multileaf collimator were used for 3D-CRT. The beam angles, wedge angles, and beam weighting (usually minimal) were chosen to optimize coverage of the PTV, while minimizing exposure to the ipsilateral lung, heart and contralateral breast. Gantry angles ranged from $42^{\circ}$ to $55^{\circ}$ for the medial fields and from $224^{\circ}$ to $232^{\circ}$ for the lateral fields for patients treated on the right side, and from $305^{\circ}$ to $322^{\circ}$ for the medial fields and from $133^{\circ}$ to $147^{\circ}$ for the lateral fields for patients treated on the left side. The fields extended $2 \mathrm{~cm}$ anteriorly of the chest to provide coverage of the "flash" region.

\section{IMRT technique}

The same beam orientations and angles of the 3D-CRT plan were used for the tangential beams of the corresponding IMRT plan. The PTV included the same PTV used for the 3D-CRT plans plus an extension into the air anteriorly of the chest of $1.5 \mathrm{~cm}$ to ensure appropriate opening of the multileaf collimator. The dose was prescribed to the PTV, and as initial dose volume constraints the IMRT prescription table provided by the XIO treatment planning system was used (Table 1). Tissue inhomogeneities were considered in the treatment planning optimization process, and the dose calculation algorithm used was "Superposition". A step-and-shoot technique was applied. An optimization with 100 iterations was then applied, and followed by a semiautomatic segmentation (minimum $3 \mathrm{~cm}$ step size). Segments with less than $\leq 2 \mathrm{MU}$ were expelled from the plan.

Dose volume histograms of the PTV and organs at risk of the 3D-CRT and IMRT plans were generated and dose parameters compared. The Homogeneity index (HI) was defined as the fraction of the PTV with a dose between $95 \%$ and $105 \%$ of the prescribed dose $\left(\mathrm{V}_{95 \%}\right.$ $\mathrm{V}_{105 \%}$ ). The Conformity Index (CI) was defined as the 
Table 1 Dose-volume constraints for IMRT plans

\begin{tabular}{|c|c|c|c|c|c|c|}
\hline Structure & Type & Rank & Objective & Dose (cGy) & Volume (\%) & Weight \\
\hline PTV & Target & 1 & Maximum & 5200 & 0 & 100 \\
\hline PTV & Target & 1 & Minimum & 4900 & 100 & 100 \\
\hline Ipsilateral lung & Organ at risk & 2 & Maximum & 2000 & 20 & 100 \\
\hline Ipsilateral lung & Organ at risk & 2 & Minimum & 1200 & 30 & 100 \\
\hline Heart & Organ at risk & 3 & Maximum & 4500 & 0 & 100 \\
\hline Unspecified tissue & Organ at risk & 4 & Maximum & 4500 & 0 & 100 \\
\hline
\end{tabular}

IMRT, intensity modulated radiotherapy; PTV, planning target volume.

fraction of the PTV surrounded by the reference dose (V95\%) multiplied by the fraction of the total body volume covered by the reference PTV dose ( $\left(\mathrm{PTV}_{95 \%}\right.$ $\left./ \mathrm{PTV}) \times\left(\mathrm{PTV}_{95 \%} / \mathrm{V}_{95 \%}\right)\right)$.

\section{Statistics}

IMRT and 3D-CRT plan parameters derived from the same patient were tested for statistically significant difference using the Wilcoxon matched pairs test. All $P$ values were two-tailed. No correction for multiple testing was used.

\section{Results}

Table 2 compares plan parameters of opposed tangential beam IMRT with conventional 3D-CRT for the adjuvant radiotherapy of the chest wall in 20 unselected consecutive breast cancer patients after mastectomy. Figure 1 demonstrates typical dose distributions of an IMRT and 3D-CRT plan of the same patient.

Concerning the PTV (chest wall), tangential beam IMRT significantly improved the conformity index compared to 3D-CRT. The maximum and mean dose was higher in the IMRT plans, but the differences were small (about 1\%). The Homogeneity Index was not significantly different between the IMRT and 3D-CRT plans.

All patients treated on the left side showed a reduction of the V70\% (percentage of volume encompassed by the $70 \%$ isodose line; corresponding to the volume receiving $\geq 35 \mathrm{~Gy}$ ) of the heart with an average of $43 \%$ $(P<0.01)$. The mean heart dose was reduced by an average of $20 \%$. The ipsilateral mean lung dose was statistically significantly reduced by an average of $21 \%$.

The mean volume and the standard deviation (1SD) of the PTV (chest wall) was $612.0 \mathrm{~cm}^{3}\left(173.7 \mathrm{~cm}^{3}\right)$, of the heart $524.2 \mathrm{~cm}^{3}\left(125.5 \mathrm{~cm}^{3}\right)$, and of the ipsilateral lung $1136.7 \mathrm{~cm}^{3}\left(244.4 \mathrm{~cm}^{3}\right)$.

\section{Discussion}

A number of studies have demonstrated a dosimetric benefit of IMRT compared to 3D-CRT for the whole breast in early breast cancer patients. Data about the impact of IMRT on the adjuvant radiotherapy of the chest wall in postmastectomy patients are scarce in the literature. There are distinct geometric differences between the target volume of the chest wall and the

Table 2 Relevant plan parameters of tangential beam IMRT versus tangential beam 3D-CRT of the adjuvant radiotherapy of the chest wall in unselected postmastectomy breast cancer patients

\begin{tabular}{|c|c|c|c|c|c|c|c|}
\hline \multirow[b]{2}{*}{$\begin{array}{l}\text { Organ } \\
\text { Parameter }\end{array}$} & \multicolumn{2}{|c|}{ IMRT } & \multicolumn{2}{|c|}{ 3D-CRT } & \multirow[b]{2}{*}{ Difference } & \multirow[b]{2}{*}{ Difference (\%) } & \multirow[b]{2}{*}{$P$ value } \\
\hline & Mean & $1 S D$ & Mean & $1 S D$ & & & \\
\hline \multicolumn{8}{|l|}{ Ipsilateral chest wall (PTV) } \\
\hline Maximum Dose (cGy) & 5530 & 146 & 5462 & 135 & 68 & 1 & 0.04 \\
\hline Mean Dose (cGy) & 5083 & 73 & 5038 & 70 & 44 & 1 & 0.04 \\
\hline Homogeneity Index & 0.73 & 0.15 & 0.77 & 0.11 & -0.05 & -6 & n. s. \\
\hline Conformity Index & 0.32 & 0.04 & 0.25 & 0.14 & 0.07 & 26 & 0.03 \\
\hline \multicolumn{8}{|l|}{ Heart* } \\
\hline Maximum Dose (cGy) & 3874 & 1729 & 4990 & 180 & -1116 & -22 & n. s. \\
\hline Mean Dose (cGy) & 704 & 295 & 877 & 272 & -173 & -20 & 0.03 \\
\hline V70\% & 5.71 & 3.40 & 10.61 & 3.68 & -4.90 & -46 & $<0.03$ \\
\hline \multicolumn{8}{|l|}{ Ipsilateral lung } \\
\hline Mean Dose (cGy) & 1129 & 188 & 1437 & 204 & -308 & -21 & $<0.01$ \\
\hline D30\% & 960 & 537 & 1695 & 875 & -734 & -43 & $<0.01$ \\
\hline
\end{tabular}

3D-CRT, three-dimensional conformal radiotherapy; IMRT, intensity-modulated radiotherapy; 1SD, standard deviation; V70\%, percentage of tissue volume encompassed by the $70 \%$ isodose line ( $35 \mathrm{~Gy}) ;$ D30\%, dose to $30 \%$ of the volume (PTV or Organs at risk); ${ }^{*}$, Patients with left-sided breast cancer only; n.s., not significant. 


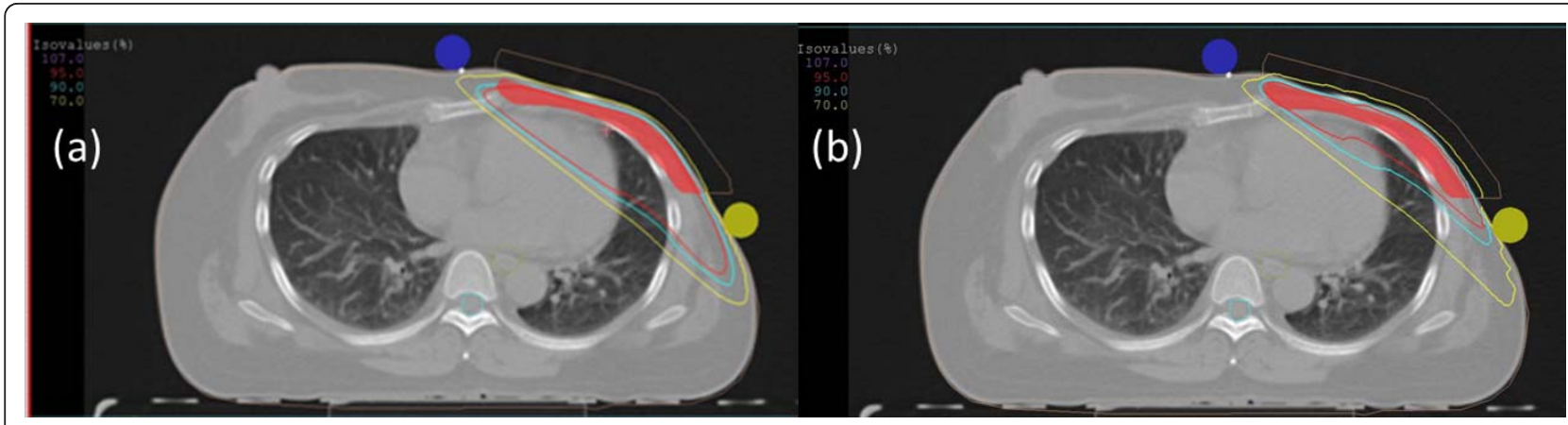

Figure 1 Dose distribution (V107\%, V95\%, V90\%, V70\%) for (a) conformal three-dimensional (3D-CRT) and (b) intensity modulated radiotherapy (IMRT) plans.

whole breast, and these differences might have an impact on the resulting dose distribution. This study was undertaken to evaluate the dose distribution of tangential beam IMRT of the chest wall compared to tangential beam 3D-CRT in unselected postmastectomy breast cancer patients.

Our data show that tangential beam IMRT of the chest wall compared to 3D-CRT significantly reduces the ipsilateral lung dose-volume (D30\% by 43\%), and heart dose-volume in patients treated on the left side (V70\% by 46\%). Similar results have been reported for tangential beam IMRT for the whole breast in early breast cancer patients. In a recent study, Smith et al. compared three tangential beam IMRT plans with conventional tangential beam $2 \mathrm{D}$ plans for the adjuvant radiotherapy of the whole breast in 20 patients with early breast cancer [52]. All IMRT plans showed a significant improvement of the PTV homogeneity index of $15 \%$, heart V30\% of $28-33 \%$, and whole lung V20\% of 2$8 \%$ compared to the conventional technique.

A significantly better sparing of the high-dose volume of the heart in selected early breast cancer patients with unfavourable thoracic geometry has been reported by the use of multifield IMRT [53,54]. Compared to 3DCRT, multifield IMRT reduced the heart volume receiving $\geq 30$ Gy by $87 \%$ [53], or $\geq 35$ Gy by $81 \%$ [54]. Model calculation using a relative seriality model [55] suggested that the excess cardiac risk was decreased from approximately $6 \%$ to $<1 \%$ in these patients [53]. On the other hand, in contrast to our study using tangential beam IMRT, multifield IMRT significantly increased the mean heart dose by an average of $24.4 \%$ [53], the left lung D30\% by $143 \%$ [53], and the volume of the left lung receiving $\geq 20$ Gy by $47 \%[54]$.

It is difficult to precisely estimate the possible clinical effect of the heart dose-volume reduction by the use of multifield versus tangential beam IMRT. Clinically recognized presentations of radiation induced heart disease have been observed in patients who received therapeutic doses of about $\geq 35$ Gy to partial volumes of the heart [56]. Recent studies based on atom bomb survivors also suggest a relationship between cardiac mortality and low radiation doses in the range of $\leq 4 \mathrm{~Gy}$ [57-60]. The development of radiation-related heart disease is a complex process involving different heart structures with different radiosensitivities and pathomechanisms, and is still not well understood [61,62]. Furthermore, pre-existing cardiovascular risk factors as smoking, obesity, and hypertension as well as the use of cardiotoxic agents such as anthracyclines, paclitaxel and trastuzumab are likely to contribute to the development of radiation-related heart disease. In view of the potential risks it has been recommended that all measures should be attempted to reduce cardiac radiation exposure [61].

An increased risk of secondary tumors has been observed in breast cancer patients treated with older radiation techniques, which combined higher radiation dose and larger tissue volumes [5,11,12,63,64]. Modern radiotherapy techniques as $3 \mathrm{D}$-CRT are likely to reduce the secondary cancer risk by reducing the lung dosevolume [65]. Smoking has been shown to significantly increase the risk of second lung cancer in radiotherapy patients even if modern radiation techniques were used $[66,67]$.

Multifield IMRT has been discussed to possibly increase the risk of second cancers [68]. The reason for this is that compared to 3D-CRT a larger volume of healthy tissue is being irradiated with lower doses due to the use of multiple beams and the high number of monitor units.

Prospective studies with long follow-up times are needed to fully evaluate the cardiac toxicity and secondary lung cancer risk in breast cancer patients treated with tangential beam or multifield IMRT.

\section{Conclusions}

Tangential beam IMRT for the radiotherapy of the chest wall of postmastectomy breast cancer patients offers the 
potential to significantly reduce the dose-volume of the ipsilateral lung, and in patients with left-sided cancer the dose-volume of the heart compared to tangential beam 3D-CRT. These results are similar to those reported for tangential beam IMRT of the whole breast in early breast cancer. In selected patients with unfavourable thoracic geometry, multifield IMRT has been shown to reduce the heart high dose-volume more effectively, but on the cost of an increased mean heart dose and ipsilateral lung dose compared to tangential beam IMRT.

\section{Abbreviations}

DX\%: Dose to X\% of the volume (PTV or Organs at risk); IMRT: Reversed planned intensity modulated radiotherapy; PTV: Planning target volume; $V X$ $\%$ : Percentage of tissue encompassed by the $\mathrm{X} \%$ isodose line, representing the volume of tissue that receives at least $95 \%$ of the prescribed dose; 3DCRT: Three-dimensionally planned conformal radiotherapy.

\section{Author details}

'Department of Radiation Oncology, Saad Specialist Hospital, P.O. Box 30353, Al Khobar 31952, Saudi Arabia. ${ }^{2}$ SAAD Research \& Development Center, Saad Specialist Hospital, P.O. Box 30353, Al Khobar 31952, Saudi Arabia.

\section{Authors' contributions}

$A A, A M$, and KA participated in the study design, carried out the dose calculation, and helped to draft the manuscript. SA participated in its design and coordination and helped to draft the manuscript. VR conceived of the study, participated in its design and coordination, participated in the treatment panning, performed the statistical analysis, and drafted the manuscript. All authors read and approved the final manuscript.

\section{Competing interests}

The authors declare that they have no competing interests.

Received: 23 January 2011 Accepted: 21 March 2011

Published: 21 March 2011

\section{References}

1. Habermann EB, Abbott A, Parsons HM, Virnig BA, Al-Refaie WB, Tuttle TM: Are mastectomy rates really increasing in the United States? J Clin Oncol 2010, 28(21):3437-3441.

2. El Saghir NS, Khalil MK, Eid T, El Kinge AR, Charafeddine M, Geara F, Seoud M, Shamseddine Al: Trends in epidemiology and management of breast cancer in developing Arab countries: a literature and registry analysis. Int J Surg 2007, 5(4):225-233.

3. Overgaard M, Nielsen HM, Overgaard J: Is the benefit of postmastectomy irradiation limited to patients with four or more positive nodes, as recommended in international consensus reports? A subgroup analysis of the DBCG 82 b\&c randomized trials. Radiother Oncol 2007, 82(3):247-253

4. Clarke M, Collins R, Darby S, Davies C, Elphinstone P, Evans E, Godwin J, Gray R, Hicks C, James S, et al: Effects of radiotherapy and of differences in the extent of surgery for early breast cancer on local recurrence and 15-year survival: an overview of the randomised trials. Lancet 2005, 366(9503):2087-2106.

5. Zablotska LB, Neugut Al: Lung carcinoma after radiation therapy in women treated with lumpectomy or mastectomy for primary breast carcinoma. Cancer 2003, 97(6):1404-1411.

6. Travis LB, Curtis RE, Inskip PD, Hankey BF: Re: Lung cancer risk and radiation dose among women treated for breast cancer. J Natl Cancer Inst 1995, 87(1):60-61.

7. Rubino C, de Vathaire F, Shamsaldin A, Labbe M, Le MG: Radiation dose, chemotherapy, hormonal treatment and risk of second cancer after breast cancer treatment. Br J Cancer 2003, 89(5):840-846.
8. Berrington de Gonzalez A, Curtis RE, Gilbert E, Berg CD, Smith SA, Stovall M, Ron E: Second solid cancers after radiotherapy for breast cancer in SEER cancer registries. Br J Cancer 2010, 102(1):220-226.

9. Fisher B, Jeong JH, Anderson S, Bryant J, Fisher ER, Wolmark N: Twentyfive-year follow-up of a randomized trial comparing radical mastectomy, total mastectomy, and total mastectomy followed by irradiation. $N$ Engl J Med 2002, 347(8):567-575.

10. Roychoudhuri R, Robinson D, Putcha V, Cuzick J, Darby S, Moller H: Increased cardiovascular mortality more than fifteen years after radiotherapy for breast cancer: a population-based study. BMC Cancer 2007, 7:9.

11. Prochazka M, Granath F, Ekbom A, Shields PG, Hall P: Lung cancer risks in women with previous breast cancer. Eur J Cancer 2002, 38(11):1520-1525.

12. Galper S, Gelman R, Recht A, Silver B, Kohli A, Wong JS, Van Buren T, Baldini EH, Harris JR: Second nonbreast malignancies after conservative surgery and radiation therapy for early-stage breast cancer. Int J Radiat Oncol Biol Phys 2002, 52(2):406-414.

13. Giordano SH, Kuo YF, Freeman JL, Buchholz TA, Hortobagyi GN Goodwin JS: Risk of cardiac death after adjuvant radiotherapy for breast cancer. J Natl Cancer Inst 2005, 97(6):419-424.

14. Darby SC, McGale P, Taylor CW, Peto R: Long-term mortality from heart disease and lung cancer after radiotherapy for early breast cancer: prospective cohort study of about 300,000 women in US SEER cancer registries. Lancet Oncol 2005, 6(8):557-565.

15. Darby S, McGale P, Peto R, Granath F, Hall P, Ekbom A: Mortality from cardiovascular disease more than 10 years after radiotherapy for breast cancer: nationwide cohort study of 90000 Swedish women. BMJ 2003, 326(7383):256-257.

16. Cuzick J, Stewart H, Rutqvist L, Houghton J, Edwards R, Redmond C, Peto R, Baum M, Fisher B, Host $H$, et al: Cause-specific mortality in long-term survivors of breast cancer who participated in trials of radiotherapy. $J$ Clin Oncol 1994, 12(3):447-453.

17. Rutqvist LE, Lax I, Fornander T, Johansson H: Cardiovascular mortality in a randomized trial of adjuvant radiation therapy versus surgery alone in primary breast cancer. Int J Radiat Oncol Biol Phys 1992, 22(5):887-896.

18. Host $\mathrm{H}$, Brennhovd IO, Loeb M: Postoperative radiotherapy in breast cancer-long-term results from the Oslo study. Int J Radiat Oncol Biol Phys 1986, 12(5):727-732.

19. Haybittle JL, Brinkley D, Houghton J, A'Hern RP, Baum M: Postoperative radiotherapy and late mortality: evidence from the Cancer Research Campaign trial for early breast cancer. BMJ 1989, 298(6688):1611-1614.

20. Jones JM, Ribeiro GG: Mortality patterns over 34 years of breast cancer patients in a clinical trial of post-operative radiotherapy. Clin Radiol 1989, 40(2):204-208.

21. Paszat LF, Mackillop WJ, Groome PA, Schulze K, Holowaty E: Mortality from myocardial infarction following postlumpectomy radiotherapy for breast cancer: a population-based study in Ontario, Canada. Int J Radiat Oncol Biol Phys 1999, 43(4):755-762.

22. Hojris I, Overgaard M, Christensen JJ, Overgaard J: Morbidity and mortality of ischaemic heart disease in high-risk breast-cancer patients after adjuvant postmastectomy systemic treatment with or without radiotherapy: analysis of DBCG $82 \mathrm{~b}$ and $82 \mathrm{c}$ randomised trials. Radiotherapy Committee of the Danish Breast Cancer Cooperative Group. Lancet 1999, 354(9188):1425-1430.

23. Patt DA, Goodwin JS, Kuo YF, Freeman JL, Zhang DD, Buchholz TA, Hortobagyi GN, Giordano SH: Cardiac morbidity of adjuvant radiotherapy for breast cancer. J Clin Oncol 2005, 23(30):7475-7482.

24. Correa CR, Litt HI, Hwang WT, Ferrari VA, Solin LJ, Harris EE: Coronary artery findings after left-sided compared with right-sided radiation treatment for early-stage breast cancer. J Clin Oncol 2007, 25(21):3031-3037.

25. Beckham WA, Popescu CC, Patenaude W, Wai ES, Olivotto IA: Is multibeam IMRT better than standard treatment for patients with left-sided breast cancer? Int J Radiat Oncol Biol Phys 2007, 69(3):918-924.

26. Dogan N, Cuttino L, Lloyd R, Bump EA, Arthur DW: Optimized dose coverage of regional lymph nodes in breast cancer: the role of intensitymodulated radiotherapy. Int J Radiat Oncol Biol Phys 2007, 68(4):1238-1250.

27. Abo-Madyan Y, Polednik M, Rahn A, Schneider F, Dobler B, Wenz F, Lohr F: Improving dose homogeneity in large breasts by IMRT: efficacy and dosimetric accuracy of different techniques. Strahlenther Onkol 2008, 184(2):86-92. 
28. Barnett GC, Wilkinson J, Moody AM, Wilson CB, Sharma R, Klager S, Hoole AC, Twyman N, Burnet NG, Coles CE: A randomised controlled trial of forward-planned radiotherapy (IMRT) for early breast cancer: baseline characteristics and dosimetry results. Radiother Oncol 2009, 92(1):34-41.

29. Caudrelier JM, Morgan SC, Montgomery L, Lacelle M, Nyiri B, Macpherson M: Helical tomotherapy for locoregional irradiation including the internal mammary chain in left-sided breast cancer: dosimetric evaluation. Radiother Oncol 2009, 90(1):99-105

30. Cozzi L, Fogliata A, Nicolini G, Bernier J: Clinical experience in breast irradiation with intensity modulated photon beams. Acta Oncol 2005, 44(5):467-474

31. Descovich M, Fowble B, Bevan A, Schechter N, Park C, Xia P: Comparison between hybrid direct aperture optimized intensity-modulated radiotherapy and forward planning intensity-modulated radiotherapy for whole breast irradiation. Int J Radiat Oncol Biol Phys 2010, 76(1):91-99.

32. Donovan E, Bleakley N, Denholm E, Evans P, Gothard L, Hanson J, Peckitt C, Reise S, Ross G, Sharp G, et al: Randomised trial of standard 2 D radiotherapy (RT) versus intensity modulated radiotherapy (IMRT) in patients prescribed breast radiotherapy. Radiother Oncol 2007, 82(3):254-264

33. Donovan EM, Yarnold JR, Adams EJ, Morgan A, Warrington AP, Evans PM: An investigation into methods of IMRT planning applied to breast radiotherapy. Br J Radiol 2008, 81(964):311-322.

34. Fogliata A, Nicolini G, Alber M, Asell M, Dobler B, El-Haddad M, Hardemark B, Jelen U, Kania A, Larsson M, et al: IMRT for breast. a planning study. Radiother Oncol 2005, 76(3):300-310

35. Harsolia A, Kestin L, Grills I, Wallace M, Jolly S, Jones C, Lala M, Martinez A, Schell S, Vicini FA: Intensity-modulated radiotherapy results in significant decrease in clinical toxicities compared with conventional wedge-based breast radiotherapy. Int J Radiat Oncol Biol Phys 2007, 68(5):1375-1380.

36. Herrick JS, Neill CJ, Rosser PF: A comprehensive clinical 3-dimensional dosimetric analysis of forward planned IMRT and conventional wedge planned techniques for intact breast radiotherapy. Med Dosim 2008 33(1):62-70.

37. McDonald MW, Godette KD, Butker EK, Davis LW, Johnstone PA: Long-term outcomes of IMRT for breast cancer: a single-institution cohort analysis. Int J Radiat Oncol Biol Phys 2008, 72(4):1031-1040.

38. McDonald MW, Godette KD, Whitaker DJ, Davis LW, Johnstone PA: ThreeYear Outcomes of Breast Intensity-Modulated Radiation Therapy with Simultaneous Integrated Boost. Int J Radiat Oncol Biol Phys 2009.

39. Moon SH, Shin KH, Kim TH, Yoon M, Park S, Lee DH, Kim JW, Kim DW Park SY, Cho KH: Dosimetric comparison of four different external beam partial breast irradiation techniques: three-dimensional conformal radiotherapy, intensity-modulated radiotherapy, helical tomotherapy, and proton beam therapy. Radiother Oncol 2009, 90(1):66-73.

40. Morganti AG, Cilla S, Valentini V, Digesu C, Macchia G, Deodato F, Ferrandina G, Cece MG, Cirocco M, Garganese G, et al: Phase I-Il studies on accelerated IMRT in breast carcinoma: technical comparison and acute toxicity in 332 patients. Radiother Oncol 2009, 90(1):86-92.

41. Popescu CC, Olivotto IA, Beckham WA, Ansbacher W, Zavgorodni S, Shaffer R, Wai ES, Otto K: Volumetric modulated arc therapy improves dosimetry and reduces treatment time compared to conventional intensity-modulated radiotherapy for locoregional radiotherapy of leftsided breast cancer and internal mammary nodes. Int J Radiat Oncol Biol Phys 2010, 76(1):287-295

42. Remouchamps VM, Vicini FA, Sharpe MB, Kestin LL, Martinez AA, Wong JW: Significant reductions in heart and lung doses using deep inspiration breath hold with active breathing control and intensity-modulated radiation therapy for patients treated with locoregional breast irradiation. Int J Radiat Oncol Biol Phys 2003, 55(2):392-406.

43. Thilmann C, Zabel A, Kuhn S, Bendl R, Rhein B, Wannenmacher M, Debus J: [Inversely planned intensity modulated radiotherapy for irradiation of a woman with breast cancer and funnel chest]. Strahlenther Onkol 2002, 178(11):637-643.

44. Fong A, Bromley R, Beat M, Vien D, Dineley J, Morgan G: Dosimetric comparison of intensity modulated radiotherapy techniques and standard wedged tangents for whole breast radiotherapy. J Med Imaging Radiat Oncol 2009, 53(1):92-99.

45. Bhatnagar AK, Beriwal S, Heron DE, Flickinger JC, Deutsch M, Huq MS, Sontag M, Shogan J: Initial Outcomes Analysis for Large Multicenter
Integrated Cancer Network Implementation of Intensity Modulated Radiation Therapy for Breast Cancer. Breast J 2009, 15(5):468-74.

46. Bhatnagar AK, Brandner E, Sonnik D, Wu A, Kalnicki S, Deutsch M, Heron DE: Intensity modulated radiation therapy (IMRT) reduces the dose to the contralateral breast when compared to conventional tangential fields for primary breast irradiation. Breast Cancer Res Treat 2006, 96(1):41-46.

47. Bhatnagar AK, Heron DE, Deutsch M, Brandner E, Wu A, Kalnicki S: Does breast size affect the scatter dose to the ipsilateral lung, heart, or contralateral breast in primary breast irradiation using intensitymodulated radiation therapy (IMRT)? Am J Clin Oncol 2006, 29(1):80-84.

48. Burmeister J, Alvarado N, Way S, McDermott P, Bossenberger T, Jaenisch $H_{\text {, }}$ Patel R, Washington T: Assessment and minimization of contralateral breast dose for conventional and intensity modulated breast radiotherapy. Med Dosim 2008, 33(1):6-13.

49. Cavey ML, Bayouth JE, Endres EJ, Pena JM, Colman M, Hatch S: Dosimetric comparison of conventional and forward-planned intensity-modulated techniques for comprehensive locoregional irradiation of postmastectomy left breast cancers. Med Dosim 2005, 30(2):107-116.

50. Gauer T, Engel K, Kiesel A, Albers D, Rades D: Comparison of electron IMRT to helical photon IMRT and conventional photon irradiation for treatment of breast and chest wall tumours. Radiother Oncol 2010, 94(3):313-318.

51. van der Laan HP, Korevaar EW, Dolsma W, Maduro JH, Langendijk JA Minimising contralateral breast dose in post-mastectomy intensitymodulated radiotherapy by incorporating conformal electron irradiation. Radiother Oncol 2010, 94(2):235-240

52. Smith W, Menon G, Wolfe N, Ploquin N, Trotter T, Pudney D: IMRT for the breast: a comparison of tangential planning techniques. Phys Med Biol 2010, 55(4):1231-1241.

53. Lohr F, El-Haddad M, Dobler B, Grau R, Wertz HJ, Kraus-Tiefenbacher U, Steil $V$, Madyan YA, Wenz F: Potential effect of robust and simple IMRT approach for left-sided breast cancer on cardiac mortality. Int J Radiat Oncol Biol Phys 2009, 74(1):73-80

54. Coon AB, Dickler A, Kirk MC, Liao Y, Shah AP, Strauss JB, Chen S, Turian J, Griem KL: Tomotherapy and Multifield Intensity-Modulated Radiotherapy Planning Reduce Cardiac Doses in Left-Sided Breast Cancer Patients with Unfavorable Cardiac Anatomy. Int J Radiat Oncol Biol Phys 2009.

55. Gagliardi G, Lax I, Soderstrom S, Gyenes G, Rutqvist LE: Prediction of excess risk of long-term cardiac mortality after radiotherapy of stage I breast cancer. Radiother Oncol 1998, 46(1):63-71.

56. Brosius FC, Waller BF, Roberts WC: Radiation heart disease. Analysis of 16 young (aged 15 to 33 years) necropsy patients who received over 3,500 rads to the heart. Am J Med 1981, 70(3):519-530.

57. McGale P, Darby SC: Low doses of ionizing radiation and circulatory diseases: a systematic review of the published epidemiological evidence. Radiat Res 2005, 163(3):247-257.

58. Preston DL, Shimizu Y, Pierce DA, Suyama A, Mabuchi K: Studies of mortality of atomic bomb survivors. Report 13: Solid cancer and noncancer disease mortality: 1950-1997. Radiat Res 2003, 160(4):381-407.

59. Shimizu Y, Pierce DA, Preston DL, Mabuchi K: Studies of the mortality of atomic bomb survivors. Report 12, part II. Noncancer mortality: 19501990. Radiat Res 1999, 152(4):374-389.

60. Taylor CW, MCGale P, Darby SC: Cardiac risks of breast-cancer radiotherapy: a contemporary view. Clin Oncol (R Coll Radiol) 2006, 18(3):236-246

61. Senkus-Konefka E, Jassem J: Cardiovascular effects of breast cancer radiotherapy. Cancer Treat Rev 2007, 33(6):578-593.

62. Darby SC, Cutter DJ, Boerma M, Constine LS, Fajardo LF, Kodama K Mabuchi K, Marks LB, Mettler FA, Pierce LJ, et al: Radiation-related heart disease: current knowledge and future prospects. Int J Radiat Oncol Biol Phys 2010, 76(3):656-665.

63. Fisher B, Anderson S, Bryant J, Margolese RG, Deutsch M, Fisher ER, Jeong JH, Wolmark N: Twenty-year follow-up of a randomized trial comparing total mastectomy, lumpectomy, and lumpectomy plus irradiation for the treatment of invasive breast cancer. N Engl J Med 2002, 347(16):1233-1241.

64. Roychoudhuri R, Evans H, Robinson D, Moller H: Radiation-induced malignancies following radiotherapy for breast cancer. Br J Cancer 2004 91(5):868-872

65. Muren LP, Maurstad G, Hafslund R, Anker G, Dahl O: Cardiac and pulmonary doses and complication probabilities in standard and 
conformal tangential irradiation in conservative management of breast cancer. Radiother Oncol 2002, 62(2):173-183.

66. van Dongen JA, Voogd AC, Fentiman IS, Legrand C, Sylvester RJ, Tong D,

van der Schueren E, Helle PA, van Zijl K, Bartelink H: Long-term results of a randomized trial comparing breast-conserving therapy with mastectomy: European Organization for Research and Treatment of Cancer 10801 trial. J Natl Cancer Inst 2000, 92(14):1143-1150.

67. Blichert-Toft M, Nielsen M, During M, Moller S, Rank F, Overgaard M, Mouridsen $\mathrm{HT}$ : Long-term results of breast conserving surgery vs. mastectomy for early stage invasive breast cancer: 20-year follow-up of the Danish randomized DBCG-82TM protocol. Acta Oncol 2008, 47(4):672-681.

68. Hall EJ, Wuu CS: Radiation-induced second cancers: the impact of 3D-CRT and IMRT. Int J Radiat Oncol Biol Phys 2003, 56(1):83-88.

doi:10.1186/1748-717X-6-26

Cite this article as: Rudat et al.: Tangential beam IMRT versus tangential beam 3D-CRT of the chest wall in postmastectomy breast cancer patients: A dosimetric comparison. Radiation Oncology 2011 6:26.

\section{Submit your next manuscript to BioMed Central} and take full advantage of:

- Convenient online submission

- Thorough peer review

- No space constraints or color figure charges

- Immediate publication on acceptance

- Inclusion in PubMed, CAS, Scopus and Google Scholar

- Research which is freely available for redistribution

Submit your manuscript at www.biomedcentral.com/submit 